\title{
Evaluating Foreign Direct Investment and Africa's Development
}

\author{
Nicholas Onyemechi Alumona \\ http://dx.doi./org/10.4314/ujah.v18i1.3
}

\section{Abstract}

The question of Africa's development has continued to occupy the front burner from the social and economic discussions by scholars of various divides. But Africa's development through foreign direct investment has become a recent challenge to the African continent. African social critics and commentators as well as Western scholars have attributed the seeming slow pace of development in Africa to several factors discouraging foreign direct investment. Suggestions and literature on how to overcome these factors abound; all calling on African states to provide the enabling environment for foreign investors under this arrangement to help in solving Africa's socio-economic problems. In this essay, we adopt the method of analysis and argue that rather than blame African states for the underperformance of foreign direct investment, policy makers should be more humanistic in entering into economic agreement with the advanced countries of the world and ensure that such agreements accommodate certain positive values of the host continent. It therefore concludes that with interculturalism as the foundation of any economic solution to Africa's development problem, whether external or homegrown, Africans would appreciate and participate more in development activities that concern them. 


\section{Introduction}

The continent of Africa, especially the sub-Saharan Africa for ages, has been described as a developing one. That is why the continent is said to need foreign direct investment, hereafter referred to as FDI. The basic issue here is what impact FDI makes in the economy of African states and what reasons account for such impacts. Does Africa really need these investments from the West? In a globalised world such as we are, the appropriateness of free and international trade between countries of the world are incontrovertible. But how much of development does such bilateral or multilateral trade relations bring to the parties involved is a fundamental issue to be addressed in this work.

Trade relations between Africa and the West have a long history; and they have always been defined by the cheapness of labour from the former's part of the world. Eric Williams observes, in his explanation of the kind of trade which existed between Africa and the West in the $18^{\text {th }}$ Century. According to him, such trade was "economic, not racial; it had to do not with the colour of the labourer but with the cheapness of labour" (389). Africa then provided the cheap labour for the sustenance of the European industries. This was described as slavery. There was, however, a transition from this trade relation to that of development through colonization. This period has been described by Eze as ".... period marked by the...occupation of most parts of Africa and the forced administration of its people, and the resilient and enduring ideologies and practices of European cultural superiority(ethnocentrism) and 'racial' supremacy(racism)" (213).

The Western idea of colonialism as should be accepted by Africans is that the colonizers alone were knowledgeable enough to determine the paradigm of civilization and development. Africans were consequently an inferior race that cannot develop in 
themselves and their self-initiated programmes. Since the mentality of Africa is primitive, it is "hardly capable of abstract thought but it is rather regulated by the forces of myth and superstition"(LevyBruhl 54). The attacks from decolonization studies and scholars further led to redefining the paradigm for Africa's development by the colonizers. The brand of Africa's development then became that which would come through neo-colonialism.

Neocolonialism, according to Bishop, David, Kastner and Nassali, means that: "...the state which is subject to it is, in theory, independent and has all the outward trappings of international sovereignty. In reality, its economic system and thus its political policy is directed from outside" (14). This explains the dominance of rich states over the seemingly poor ones. It is in line with this last submission that these scholars further avow that:

...the result of neo-colonialism is that foreign capital is used for exploitation rather than for the development of the less developed parts of the world. Investment under neocolonialism increases rather than decreases the gap between the rich and the poor countries of the world (14-15).

This is the class into which FDI as a policy for economic development falls in. However, the advocates of this approach to development would not admit it as connected to neocolonialism, simply because it appears to be a derogatory view. They rather prefer seeing this approach as a neo-liberal approach to economic development. It is from this framework of admitting FDI into the matrix of neo-liberalism as an economic approach that we discuss how much Africa needs it as a solution to her economic woes. 


\section{Conceptualizing Foreign Direct Investment (FDI)}

The guiding principle for the definition of FDI is from the World Bank, the International Monetary Fund (IMF) and the Organization for Economic Co-operation and Development (OECD). In the view of all three organizations, FDI as an economic policy is meant to secure almost a permanent interest of a resident entity (referred to as the direct investor) from a country in an economic enterprise of another country. This enterprise in a foreign country is called the direct investment enterprise. Olusanya explicitly defines FDI, based on a 1996 World Bank report, as "an investment made to acquire a lasting management interest(normally $10 \%$ of voting stock) in a business enterprise operating in country other than that of the investor defined according to residency" (335).

FDI takes certain forms such as: (i) the Greenfield investment: This is the kind of investment that involves the establishment of new enterprises or putting investment resources on already existing enterprises (ii) Merger and Acquisition: In this type of investment, the investor acquires already existing interests instead of establishing new ones. (iii) There is also the reinvestment of the earnings from an existing enterprise. This reinvestment also grants capital transfer between the parent companies and their affiliates. The entire process of FDI stands on Dunning's 'OLI' paradigm of operation as clearly explained by Onyeagu and Okeyika (1136-1137). This acronym stands for ownership, location and the internal management of the enterprise. The first of the paradigm grants investors the power to relocate their own production abroad whenever they wish to, especially when they deem it more profitable to do so. The second aspect permits the investor to chose wherever he sees profitable to locate his investment and lastly, the investor ought to determine how much to manage his enterprise internally. All these show that 
investors operating on FDI have enormous power of decisions, regardless of the condition of the host. Having briefly explained what FDI means, it is important to examine its necessity in global economy, especially as it affects Africa in her development goals. A number of reasons and explanations have been given on why Africa needs investors on the arrangements of the FDI if she actually desires development.

\section{The Impacts of Foreign Direct Investment in Africa as a Developing Continent}

In the introductory section of this work, we discussed the lopsidedness of the several trade relations and agreements entered into between Africa and countries of the West. But on the contrary, there are certain positives that various scholars, development economists and policy makers have brought forward on why developing countries in need of development should be part of the free trade policy in the global economy. Such positives include but not limited to: (i) technology transfer (ii) development of human capital (iii) integration into the global economy; and (iv) poverty reduction.

Technology Transfer: Harry, highlighting what technological transfer means, says that:

Technology, most often, are invented or developed in one country. But utilized and enjoyed in different parts of the world. The process through which technology invented in one part of the world is utilized or enjoyed in other parts of the world is what is generally referred to as technology transfer or technology diffusion (120). 
The developing countries of the world, Africa inclusive, lack scientific and technological knowledge, skills and techniques needed for their own development. Yet there are sensitive sectors of the economy of African states in which we inevitably desire technology in order for us to access the natural resources that also contribute to the development of the continent.

It is in view of the above picture where developing countries lack the technological wherewithal to help themselves that the United Nations recommends and supports the transfer of technology from the industrially advanced countries of the world to the developing countries mainly through the activities of the Trans-national corporations (TNCs). This is emphasized in a United Nations' report in which it is avowed that:

One of the most important contributions that host developing countries seek from TNCs investing in their economies is technology. This is because a large proportion of the generation of commercially significant technology takes place within TNCs that accordingly play a significant role in its transfer and diffusion. Indeed, the international market for technology is dominated by such firms (UNCTAD 12).

This dependence of the developing countries on the TNCs takes two forms: internalized and externalized. The transfer of technology with the former is by direct investment and exclusively by the TNCs while that of the latter include: minority joint ventures, sale of capital goods, original equipment manufacturing, licences which can also, apart from the TNCs, be provided by purely national firms (UNCTAD, Foreign 18). In spite of the seeming role national firms are supposed to play in economic 
development in this latter form of transfer, in reality the TNCs play such roles because of their ownership of technology.

Human Capital Development: This is another area where developing countries are seen to have benefitted from the FDI. And this perception of the benefits enjoyed by African states from the FDI is advanced by the supporters of such policy. In order for us to recap what this concept is all about, it is important to first highlight the concept of human capital as "the knowledge, skills, competences, and attributes embodied in individuals that facilitate the creation of personal, social and economic well-being" (18). It is against this background that Marimathu, Arokiasamy and Ismail define human capital development to mean:

The processes that relate to training, education, and other professional initiatives in order to increase the levels of knowledge, skills, abilities, values, and social assets of an employee which will lead to the employee's satisfaction and performance, and eventually on a firm's performance (266).

This definition seems to revolve around the economic output from a trained individual, thus narrowing human capital development to improving the human capacity in various areas of life with the sole intent of receiving economic gains in return. But from the OECD's definition of human capital, it is clear that human capital development is much broader than that because beyond the economic well-being of the individual, it also takes cognizance of the need for the individual development himself. It also shows interest on how such development fosters a good relationship between an individual and his fellow human beings as well as between him and the entire community of other individuals and 
institutions. In spite of this broad view of human development, it is also important to state that the perspective of OECD notwithstanding, organizational competencies and efficiencies is the primary aim of human capital development. This is because the efficiency such development portends culminates in increase in productivity.

Integration into the Global Economy: A country that encourages FDI frees itself from indigenous protectionist policies which hamper the possibilities of economic growth accruing from our contemporary world of globalization. These indigenous policies which are promoted by the traditionalists, according to Oladipo, "do not recognize the connection between collective world outlooks and their socio-economic basis nor do they appreciate the changing nature of these worldviews, changes which are linked to general societal transformations" (Oladipo 34). He, however, supports the analytic orientation which would enable us tackle the weaknesses of our protectionist principles and critically accept the modern values and practices that constitute development in the contemporary mental outlooks of a globalised world. It is from this latter perspective, that all countries of world are urged to make their countries free trade zones for every other country to legitimately trade in since such practices make for the possibility of global integration.

Most literature understandably avow that rather than FDI resulting in integration of countries into the global economy, as it is seen in this paper, conversely it is how much a country is integrated into the global economy that determines the level of foreign investment that are attracted into the country( Ngongang 16-17). But exactly how does FDI ensure global economic integration? As already acknowledged, global economic 
integration may be seen as the foundation of FDI in host countries but the level of private and foreign investment by persons and corporations in countries outside their own also determines the willingness of benefitting countries to desire integration into the global economy. There is also the extension of such desires to other countries that have seen the impacts of FDI in countries that attract them. Such investments can result in integration into the global economy rather than the converse situation that is popularly held by many scholars. So how much the multilateral bodies and transnational corporations invest in countries, especially in developing ones, determines the level of interest to be shown in being integrated into the world economy. Therefore, economic gains from investment made by these multilateral and bilateral agencies can encourage other private investors to go into investing in foreign countries.

Poverty Reduction: The level of poverty in the least developed countries (LDCs) and developing countries is put at a very high rate all year round. At this point an attempt at conceptualizing poverty will be done. It goes beyond its ordinary lexical understanding which is negatively defined as the absence of wealth. The World Bank definition is a guide for us in this work. In its view, it entails the:

Deprivation in well-being and comprises many dimensions. It includes low incomes and inability to acquire basic goods and services necessary for survival with dignity. Poverty also encompasses low levels of health and education, poor access to clean water and sanitation, inadequate physical security, lack of voice, and insufficient capacity and opportunity to better one's life (cited in Assadzedeh \& Pourqoly 161). 
Obviously then, poverty reduction becomes the amelioration of those conditions listed above. This means that whether as transfer of technology, human capital development or integration into the global economy, FDI is meant to end in the creation of employment, provision of better income for workers in the host countries, ensures the acquisition of basic amenities for daily living and creating competitive environment for businesses, among other benefits.

In the eyes of the designers of FDI, one way it assists in the reduction of poverty is by instituting a more competitive business environment. It is a position of private investors to increase productivity where there are scarcity of goods and services. With local knowledge and equipment, domestically owned business enterprises cannot produce enough for themselves and their teeming population. That is why the services of these TNCs are needed, especially in the developing countries where there is a dearth of state-of-the-art technological facilities. When these TNCs come into their host countries and increase productivity, there is a resultant fall in the cost of goods and services. This is due to the fact that every competitor attempts to outdo his opponent in the market and creates room for the patronage of his own goods. Individuals can then acquire needs that are basic to them; poverty is reduced and better standard of living is created. This scenario really ensures that the host economy benefits from state-of-the-art technology and know-how as well as avoids concentrating on the goal of making abnormal profits from the host country.

\section{Examining the Appropriateness of Foreign Direct Investment in Addressing Africa's Development Questions}

All the above mentioned impacts are universal effects of FDI where ever they are attracted. This means that in Africa, these 
impacts should also be practically seen as solving the development challenges bedeviling the continent. How this has been the case since the adoption of this neo-liberal economic policy in this present world of globalisation is our preoccupation in this section. In the preceding section, we identified that the acclaimed ultimate goal of FDI is to reduce poverty in the host countries of the investors, which are mostly developing countries such as we find in Africa.

It is quite evident, judging from the living standard in Africa, that the increase in the FDI attracted to Africa in recent years have not yielded the desired ultimate goal of reducing poverty neither have they affected the lives of people in line with development plans. But to prove this claim, we need to discuss this section within the framework of some basic questions. How is FDI a neo-liberal approach to development? Is its failure of achieving the identified ultimate goal in Africa because it is neoliberal or because Africa has not provided the needed indices for it to thrive? Can the application of this neo-liberal economic policy in Africa be modified to yield its desired result or it should simply be jettisoned? Let us begin the answers to these questions by looking at what the neo-liberal view of development is and how FDI qualifies as a neo-liberal perspective to development.

In the words of Harvey:

Neo-liberalism is in the first instance a theory of political economic practices that proposes that human well-being can be ensured by liberating individual entrepreneurial freedoms and skills within an institutional framework characterized by private property rights, free markets and free trade. The role of the state is to create an institutional framework appropriate to such practice. The state has to guarantee, for example, the quality and integrity of money. 
It must also set up those military, defenses, police and legal structures and functions required to secure private property rights.... State intervention in markets (once created) must be kept to a bare minimum because, according to the theory, the state cannot possibly possess enough information to second-guess market signals (prices) and because powerful interest group will inevitably distort and bias state interventions (particularly in democracies) for their own benefits (2).

The description above characterizes the policy of FDI. The basic arrangement that attracts private foreign investors to the policy of FDI is that of the utmost freedom of the investors to own, locate and manage the internal affairs of the foreign enterprises. As an economic policy, FDI can only thrive where countries approve of the opening of their borders for free trade and investment without really being determinants of what a larger part of the investment should take care of. FDI is therefore a product of neo-liberal policies such as globalization, deregulation and privatization among others.

As a neo-liberal economic policy, the major claim of FDI is that a free market economy without the intervention of the state can yield maximum output in handling the development challenges of countries. The level of freedom of the market is also encapsulated in the idea of regulation, reduction and subsequent abolition of tariff regimes of different countries. Another aspect of FDI here which affirms it as a neoliberal economic policy is that it also ensures macroeconomic stability. In this aspect, the demand of investors is that the state should abolish all types of subsidy and government social services spending. This again explains the fact that FDI is evident in a capitalist economy. Turning to the second 
question in this section, it can be rightly said that the failure of FDI as a policy in Africa is more attributable to the exclusivist nature of the policy than the non-provision of the enabling indices by Africans and African governments. FDI comes with certain alien principles that make Africans spectators on the implementation of such policies. African governments may have consented to the policy but without the involvement of their people who should provide the indices for the flourishing of the policy. A few of the principles that come with FDI will buttress our position that there is a degree of incompatibility between FDI principles and certain values that Africans are identified with. Such accompanying principles of FDI include: competition, individuality and individual rights, survival of the fittest and independence. A discussion of one or two of these principles will suffice.

Competition is the life wire of FDI and it carries the idea that rivalry brings out the best in human beings. The purpose of competing is to win and this goes with the act of undoing one's opponent in the process of ensuring victory. This is the point Arnsperger captured when he poignantly said:

Pushing the other aside as I would a material obstacle as part of the 'totality' which obstructs my passage is, ontologically speaking, a form of killing, even if biological life is not in all cases threatened. In a metaphorical sense, firms can 'kill' one another on a market; customers can 'kill' a firm by arbitrating away from it in favour of another firm; and another people can 'kill' one another in competing for jobs or positions. In a much more literal sense, a firm can kill people if it decides to relocate and move from one country to another almost overnight, leaving all its former employees with the choice between 
being jobless and uprooting their current way of life by moving (12-13).

Even though, in principle, helping domestic enterprises grow technologically and in the knowledge of their economy is part of the operations of FDI as a policy, we know that most local firms collapse in the face of this competition. Some others, as a result of the attendant principle of the survival of the fittest, relocate to other areas they can survive instead of becoming moribund where they are. Without being rigid in our assessment of the conditions of trade, it is understandable to look for greener pasture as we engage in economic activities to eke out a living. However, such relocation ought to be done by giving the locals, especially the employees, a sense of inclusiveness in taking decisions that affect them.

Individualism and the rights of the individual is another attendant principle of FDI. As said above, the state ought not to intervene in the running of the business of these individual corporations. They can only play regulatory roles when occasion demands. Benabou and Tirole aver that:

Economists' view of how society should be organized has traditionally rested on two pillars. The invisible hand of the market, described in Adam Smith, harnesses consumers' and corporations' pursuit of self-interest... The state corrects market failures whenever externalities stand on the way of efficiency, and redistributes income and wealth, as income and wealth distribution generated by markets has no reason to fit society's moral standards (1).

The minimalist role of the state in FDI smacks of extreme methodological individualism. Profit maximization is the visible propeller of the market forces determining the society; the market 
forces are not unseen as Adam Smith says. Rather, they are the activities of individual players in the economy. These players cash in on the individualist framework of FDI to focus on rights rather than duty and responsibility to their host. Another area of concern that has brought so many questions on the actual roles of FDI in the development of Africa is the level of attainment of the supposed universal impacts of the policy. We recall that transfer of technology, human capital development, integration into the global economy and poverty reduction are some of the major impacts FDI brings to the host countries of the policy. But how has the policy fared in these areas as it relates to Africa's development? Available statistics show that FDI has considerably increased over the years in Africa. A panoramic view of FDI inflow in Africa from the late 1990s shows that Africa attracted 30.6\% FDI between 1980 and 1984 and between 1995 and 1999, annual FDI inflow to Africa hit US\$170 million.

The sub-Saharan African region on its own from 20102012 attracted average annual FDI of 55.8\%. In this region, Nigeria and Ghana have recently attracted special attention. Nigeria with $\$ 7.36$ billion has taken over from Angola while Ghana rose from $\$ 860$ million in 2007 to $\$ 1.67$ billion in 2011(Kudaisi 21-23). Much of these investments have been in the extractive sectors. But with such increase in FDI, why are there no commensurate impacts? Why can we not be real recipient of the kind of technology that will enable us explore, refine our oil and export the products? Why are we still rated very poorly in the global economic index? On the basis of elementary understanding of the law of market forces propagated by FDI policy makers, one would have thought that the increase in FDI brings about increase in those impacts discussed above. Unfortunately, it has not been so. This situation has generated several debates on the genuine 
goals of the policy. On the basis of the individualist and seeming self-centred attitudes that come with FDI, the room for suspicion on the real intent of the policy is therefore created. With this level of suspicion, there is less participation of the locals in programmes emanating from this economic policy. The question now is whether we should completely jettison FDI as a policy in favour of our own African grown development policy or we should modify it in such a way that African values will be preserved and appreciated. Based on two important experiential activities in our present world, interculturalism and globalization, it would be unwise to recommend complete jettisoning since no one continent or race can solve its challenges alone without a form of collaboration with some other parts of the world. We, therefore, hold that the modification of FDI to be grounded on certain African values would be a better option to adopt.

\section{Redefined Foreign Direct Investment and Africa's Development}

It should be realized that FDI as it operates now puts into cognizance only two major players in economic development, namely the market and the state. Both the state and the market are independent of each other and occupy separate points in economic development. In the FDI development policy, orthodox and development economists promote the view of self-autonomous individuals who allow for the determinant of people's fate by the market forces with insignificant or no state intervention. However, it is our position in this paper that there are five fundamental players in the FDI development process: state, market, multilateral bodies, people and the policy itself. The inclusive consideration of all these together exposes certain principles that define African 
cultural values which can help in the modification of this policy approach to the tackling of the challenge of development in Africa. One of the principles that emanates from our modification of FDI is that as a policy, it ought not to exclude the anthropological centredness in development. The way FDI is designed, it appears it is just a policy that is lifted from elsewhere and transported to Africa just to develop the people without the people's involvement. This is due to the fact that FDI adopts the exogenous kind of development with its foundation on that kind of metaphor by John Williamson that the "World is flat" (1330), thus assuming universal applicability.

Related to the above principle is that of our African sense of community and cooperation which would definitely bring those five fundamental players together. This will ensure inclusiveness and participation in development policies and programmes, and adaptability of the FDI policy within some of Africa's cultural matrices. Jim Harries captures it analogically when he expressly states that:

One person entering a larger community will be the one expected to adjust to the ways of that community and not vice-versa, so indeed any new input of any sort into a community will need to adjust to take it on board(or eject it), but that adjustment will basically be on its own terms(378).

We also observe here that development goes beyond the ideas of automatic price adjustments, perfect markets and efficient allocation of resources (Ntibagirirwa 122). It does not always hold that every economic theory must apply in all cultures and circumstances. Variations in culture and other orientations should be taken into consideration when establishing a policy. 
One of the elements of African ethics that can redefine FDI for it to be more appreciated is the concept of reciprocity as against that of competition which is the defining concept of FDI as conceived by the multilateral bodies. We say 'as conceived' here because we are aware that the etymological meaning of competition is at variance with its 'economistic' interpretation. While the 'economistic' understanding is based on profit maximization, the etymological view means 'seeking together'. This latter view is in consonance with reciprocity as a cultural value. In the practice of this moral concept, there is the attitude of returning the favour one has done to you. This is not necessarily quantifiable, that is why it is seen as an ethical attitude.

A corporate body known as The Group of Lisbon gives the root meaning of competition to originate from two Latin words: cum and petere, a combination of both means seeking together (xii). The idea of jointly seeking for solution to a challenge is the commonality of purposes. In the joint activity of tackling the development challenges in Africa, it does appear that the West have more of the capital resources while Africans provide other resources such as labour, manpower, market size, political and environmental stability among others. While competition in the 'economistic' sense creates the structure for FDI to exploit those resources provided by Africans, reciprocity ensures that FDI is structured in such a way that the policy identifies that everyone has a role to play and each role should be humanely rewarded.

Related to reciprocity is responsibility. Reciprocity leaves all parties to an activity with certain level of responsibility that activities geared towards profit maximization, like FDI, does not. Fahlquist gives a picture of this kind of responsibility in two senses namely: retrospective or backward-looking and prospective or forward-looking kinds of responsibility. While retrospective 
responsibility talks about one owning up to his shortcomings of the past, prospective responsibility emphasizes on taking bearing the task of future actions (n.p). Understanding responsibility in these two senses also leaves both the agent and the recipient of development programmes and policies with the consciousness of performing actions that will benefit not just themselves but also the entire community. We know there is the western-styled corporate social responsibility carried out by the TNCs which are undoubtedly designed in consideration of their profit margin and which, most times, can be optional. In this restructuring, however, we are talking of both individual and corporate responsibility in the moral sense of responsibility.

Here responsibility is a burden on the TNCs and their host(s) to perform actions for the general benefit and common good of the people. Many TNCs even abandon their own designed corporate social responsibilities without any punishment to serve. Farmlands and residential property are destroyed with little or no compensation for the locals. Benabou and Tirole give an example of this situation in Ethiopia, in their assertion that "...private investors have been evicting many peasant farmers and pastoralists in Ethiopia" (2). In view of the ugly effects of this policy as evident in most African countries, there is the need to impute morals into FDI to enable it become humanistic as a development policy.

Another area that can bring about domesticating FDI in Africa is the principle of solidarity. This is not just a concept but a way of life among Africans. We can find this attitude in many Igbo proverbs such as: Mmadu bu ike ibe meaning man is the strength of his fellow man, Eziza dini uku ogbu'egizhi meaning the solidarity of each stick of broom with others making themselves a bunch enables them to easily kill a fly. Tosam writing on solidarity 
in the Kom culture of Cameroun says: "in the Kom society, there is a deep sense of common concern and understanding between members of the community. There is concern for each other's problem" (39). Again, one foundational element of solidarity is that element of oneness of purpose. There are two commonest senses of solidarity: one is the sense in which everyone identifies a challenge and decides to tackle such as a group. The second is the sense in which an individual or a group sees a challenge or problem faced by another individual or group and identifies with the one facing such a challenge. In this second sense, identifying with the one facing the challenge can just be on the basis of empathy or for the purpose of solving the problem(s). It is in the second sense that the FDI policy can be classified. This is because the Western-based multilateral bodies having seen the visible development challenges of Africa identified with Africa, in solidarity, and introduced the FDI policy as one of the ways of saving Africa from her development woes.

But if the FDI policy is genuinely for Africa's development, how much technology transfer has it brought to Africa? In the Human Development Index (H.D.I.), how is Africa rated? Harry, for instance, further says that after over half a century of oil exploration and production in Nigeria, we cannot boast of indigenous technology for such extractive activities. Of over 115 million people using cell phones in Nigeria, we do not have any indigenous phone company (125). In the real African perspective to solidarity, the agent rescuing the 'patient' teaches the 'patient' how to tackle same challenges when they recur and even ones that have not occurred and may never occur. There is an African proverb among the Ukwuani people of Nigeria which explains this view: Ogo bu nli falin'eze n'ijuefo meaning that assistance is like food remnant stuck in between one's teeth, which 
does not satisfy one's hunger. It is not that assistance is not appreciated but in this perspective, the African feels that empowering him with the knowledge to combat problems is more beneficial in the long run and speaks more of a genuine solidarity. This is the kind of solidarity that FDI should inculturate in order to genuinely tackle Africa's development challenges.

\section{Conclusion}

In the preceding section, we discussed the roles African values can play in modifying the FDI economic policy as designed by the multilateral bodies as supported by some world powers. There are lots of other African values that also needed attention in this remodeling project of FDI but we have only picked a few of these on the conviction that our message can still be delivered. We may be accused of romanticizing African cultural values as if they are devoid of certain shortcomings like those of the West pointed out here in this discussion. We acknowledge the fact of a non-purist position on African values, hence we chose the terminology: positive African cultural values. These ones too obviously have their own lapses when overstretched but because they are rooted in the communal and humanistic framework and do not manifest personalized rationality.

Moreso, in the fusion with FDI, they do not stand on their own; they are only in collaboration with the policy to ensure more efficiency. The contention of this work is that the foundation of competition and profit maximization of the FDI policy is exclusivist both in nature and in implementation. That is why it has not made any meaningful impact in Africa. We also hold that the low performance of the FDI policy is not much of the lack of enabling environment in Africa as it is the problem of exclusion of Africa by countries of the West. It is on this basis that we advocate 
for the infusion of several African values that can promote this policy by involving the host continent as their relevant indigenous knowledge is also promoted. This will eventually culminate in an appreciable level of endogenous development; a development that is geared towards participation and interaction of multiplicity of values from all cultures of the world.

\section{Nicholas Onyemechi Alumona}

Department of Religious Studies and Philosophy

Delta State University, Abraka mandymachi@yahoo.com

\section{Works Cited}

Arnsperger, C. Competition, Consumerism and the 'Other': A philosophical Investigation into the Ethics of Economic Competition. Louvain-la-Neuve: Institute de Researches Economiques, 1996.

Assadzadeh, Ahmad and Javad Pourqoly. "The Relationship between Foreign Direct Investment, Institutional Quality and Poverty: Case of MENA Countries". Journal of Economics, Business and Management 1.2 (May 2013), 161-165.

Benabou, Roland and Jean Tirole. "Individual and Corporate Social Responsibility”. Economica. 77 (2010), 1-19. Bishop, Sarah, Cecily David, Kay Kastner and Faridah Nassali. "Colonialism, Nationalism and Neocolonialism". www.columbia.edu/kjk2124/pol_Dev_3 ${ }^{\text {rd }}$-World.

Accessed 20/04/2014. 
Eze, Emmanuel Chukwudi. "Modern Western Philosophy and African Colonialism". Emmanuel Chukwudi Eze (ed.). African philosophy: An Anthology. Oxford: Oxford Blackwell Publishers, 1998, 213-221.

Fahlquist, Nihlen Jessica. "Moral Responsibility for Environmental Problems-Individual or Institutional?" Journal of Agricultural and Environmental Ethics 2008. http://www.ethics and technology.eu/wp_content/uploads/2012.

Harries, Jim. "Translation and the Language of Implementation of Third-World Development-A Study on Sustainability in Nigeria". Journal of Sustainable Development in Africa 12.3 (2010), 373-386.

Harry, Deinibiteim Monimah. "Research, Technology, Transfer and Socio-economic Development in Nigeria: Some Lessons from the Asian Economics". Mediterranean Journal of Social Sciences 4.8 (September 2013), 119-139. Harvey, David. A Brief History of Neoliberalism. Oxford: Oxford University Press, 2005.

Kudaisi, B.V. "An Empirical Determination of Foreign Direct Investment in West African Countries: A Panel Data Analysis". International Journal of Development and Economic Sustainability 2.2 (June 2014), 19-36.

Levy-Bruhl, Lucien. "How Natives Think". Albert G. Mosley (ed.). African Philosophy: $\quad$ Selected Readings. New Jersey: Prentice Hall/Engelwood Cliffs, 1995, 40-55.

Marimuthu, Maran, Lawrence Arokiasamy and Maimunah Ismail. "Human Capital Development and its Impact on Firm Performance: Evidence from Developmental Economics". The Journal of International Social Research 2.8 (Summer 2009), 265-272. 
Ngongang, Elie. "New Regionalism in sub-Saharan Africa: A Means to Attract Foreign Direct investment (FDI) and to Legitimate Democratic Governments". African Journal of Political Science and International Relations 3.1(Jan. 2009), 015-026.

Ntibagirirwa, Symphorien. Philosophical Premises for African Economic Development: $\quad$ Sen's Capability Approach. An Unpublished PhD Thesis, University of South Africa, 2012.

OECD. The Well-being of Nations: The Role of Human and Social Capital, 2001. www.oecd.org/site/world. Accessed 21/04/2014.

Oladipo, Olusegun. The Idea of African Philosophy: A Critical Study of the Major Orientations in Contemporary African Philosophy, Ibadan: Hope Publications, 2000.

Olusanya, Samuel Olumuyiwa. "Impact of Foreign Direct Investment Inflow on Economic Growth in a Pre and Post Deregulated Nigerian Economy: A Granger Causality Test (1970-2010)". European Scientific Journal 9.25 (September 2013), 335-356.

Onyeagu, Augustina Nkechi and Kenechukwu Okezie Okeiyika. Investigating the Interaction and Human Capital on Growth: Evidence from Nigeria. Asian Economic and Financial Review 3.9 (2013), 1134-1151.

The group of Lisbon. Limits to Competition. Cambridge Massachusetts: MIT Press, 1995.

Tosam, Jerome Mbih. "The Relevance of Kom Ethics to African Development". International Journal of Philosophy 2.3 (2014), 36-47.

UNCTAD. Foreign Direct Investment in Africa: Performance and Potential. Geneva: United Nations, 1999.

UNCTAD. Transfer of Technology. Geneva: United Nations' Paper Series, 2001. Williams, Eric. "The Origin of Negro Slavery". E. C. Eze (ed.). African Philosophy: An Anthology. Oxford: Oxford Blackwell Publishers, 1998, 382-396.

Williamson, John. "Democracy and the Washington Consensus". World Development 21(1993), 1329-1336. 